\title{
Profile of Congenital Hypothyroidism patients at Hasan Sadikin General Hospital, Bandung, Indonesia 2010-2012
}

\author{
Faisal Bukkar ${ }^{*}$, RM Ryadi Fadil \\ From 7th APPES Biennial Scientific Meeting \\ Nusa Dua, Bali. 14-17 November 2012
}

\section{Background}

Congenital hypothyroidism $(\mathrm{CH})$, is caused by inadequate production of thyroid, represent one of the most common preventable causes of mental retardation. Undetected near birth, $\mathrm{CH}$ clinically manifests as mental retardation, coarse facial features, poor growth, deafness and neurological abnormalities.

\section{Objective}

To describe characteristics of patient with congenital hypothyroidism diagnosed in Pediatric Department of Hasan Sadikin General Hospital, Bandung, Indonesia

\section{Methods}

We reviewed 26 children with congenital hypothyroidism confirmed by thyroid scintigraphy from October 2010 to June 2012 who came to Dr.Hasan Sadikin General Hospital Bandung, Indonesia.

\section{Results}

Twenty six subjects were diagnosed with congenital hypothyroidism, consisted of 15 (57.7\%) girls and 11 (42.3\%) boys, mean age $11.42 \pm 10.35$ month. The youngest age when the diagnosis $(\mathrm{CH})$ was established was 2 months and the oldest was 46 months. Thirteen subjects (50\%) were referred by primary care pediatrician, 5 subjects (19.2\%) by general practitioners, 4 subjects by neuropediatrician and 4 subjects by growth and development clinic. The main presenting complaints in $\mathrm{CH}$ were global delayed development $(69,2 \%)$, constipation (50\%), prolonged icteric (15.4\%) and growth retardation (13.5\%). The most common of clinical appearance were hypotonia
(69.2\%), coarse faces (46.2\%), mottled (34.6\%), large fontanel (34.6\%), umbilical hernia (23.1\%) and macroglossia (26.9\%). We found 25 subjects were diagnosed as primary $\mathrm{CH}$ and only 1 case with secondary $\mathrm{CH}$. The most common etiology of $\mathrm{CH}$ was thyroid agenesis (53.8\%), thyroid ectopic (19.2\%), thyroid hypoplasia (11.5\%) and dyshormonogenesis (11.5\%). Decreased fT4 value were found in all subjects (mean $0.553 \pm 0.35 \mathrm{ng} / \mathrm{dl}$ ) and mean TSHs value at presentation was $31.02 \pm 20.71 \mathrm{mIU} / \mathrm{L}$. Of the 26 late diagnosed $\mathrm{CH}$ cases, $46 . \%$ had mental and motor development delay, $23.1 \%$ short stature and mental retardation, and $15.4 \%$ mental retardation and neurological sequel as complications.

\section{Conclusion}

Late diagnosis of congenital hypothyroidism in children result varied clinical manifestation and had mental retardation, gross motor delay, short stature and neurological abnormalities as complications.

Published: 3 October 2013

doi:10.1186/1687-9856-2013-S1-P141

Cite this article as: Bukkar and Fadil: Profile of Congenital

Hypothyroidism patients at Hasan Sadikin General Hospital, Bandung, Indonesia 2010-2012. International Journal of Pediatric Endocrinology 2013 2013(Suppl 1):P141. 